Max-Planck-Institut für demografische Forschung

Max Planck Institute for Demographic Research

Konrad-Zuse-Strasse 1 - D-18057 Rostock - GERMANY

Tel +49 (0) 3812081 - 0; Fax +49 (0) 3812081 - 202;

http://www.demogr.mpg.de

MPIDR WORKING PAPER WP 2010-014

FEBRUARY 2010

\title{
The Increasing Importance of Economic Conditions on Fertility
}

Deniz Dilan Karaman Örsal (karaman@demogr.mpg.de)

Joshua R. Goldstein (goldstein@demogr.mpg.de)

(C) Copyright is held by the authors.

Working papers of the Max Planck Institute for Demographic Research receive only limited review. Views or opinions expressed in working papers are attributable to the authors and do not necessarily reflect those of the Institute. 


\title{
The Increasing Importance of Economic Conditions on Fertility
}

\author{
Deniz Dilan Karaman Örsal, Joshua R. Goldstein, \\ Max Planck Institute for Demographic Research, Rostock, Germany
}

February 26, 2010

\begin{abstract}
This paper investigates whether there has been a fundamental change in the importance of economic conditions on fertility. Through the 1980s econometric studies had found at best a mixed, neutral or negative effect of economic conditions on fertility. Notably, Butz and Ward (1979) concluded that fertility was counter-cyclical, with fertility falling in good times, as the opportunity costs of childbearing rose. More recently, there have been signs that fluctuations in fertility have been pro-cyclical, with good economic times being associated with higher birth rates, and the recent recession with lower birth rates. In this paper, we use panel methods to study short term changes in aggregate fertility and economic measures in OECD countries from 1976-2008. We find indeed that fertility became positively associated with good economic conditions. Furthermore, the increasing importance of economic conditions was detected for both tempo and quantum.
\end{abstract}

\section{Introduction}

The aim of this study is to investigate whether fertility has become more responsive in recent years to economic conditions. It appears that the total fertility rate (TFR) in some OECD countries has tracked fairly closely general measures of economic conditions like unemployment. An example can be seen in Figure 1 for the Netherlands, where in recent years the rise in fertility is accompanied by the decrease in unemployment rate. In this paper, we investigate how widespread this connection is, what the possible effects of the recent economic recession on fertility might be, and explore if and when the relationship between economic conditions and aggregate fertility may have changed.

The economic conditions play a more important role on the determination of the fertility behavior in comparison to 30 years ago, because since then there is a transition from oneearner families to dual-earner families. The main reason for this phenomena is the reduction in the relative male wages, which encouraged women to take more part in the working life. 
The increasing participation of the females into the labor market, lead them to postpone childbearing, as they do not want to lose their gained power and skills by giving up their jobs to take care of their new born children.
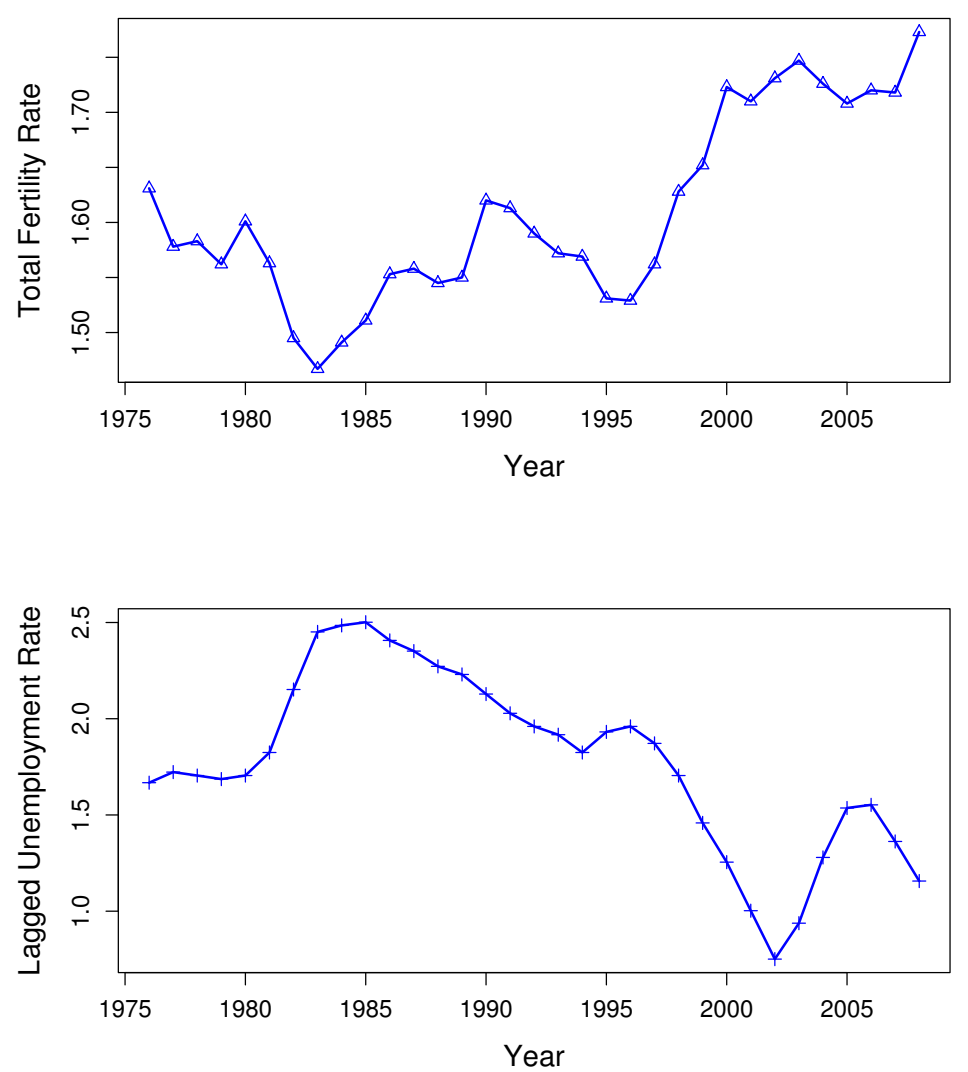

Figure 1: Total Fertility Rate and Lagged Unemployment Rate for the Netherlands

According to New Home Economics Theory, the rise in the female and male wages has different effects on fertility (see Becker, 1960, Mincer, 1963, Becker and Lewis, 1973, Mincer, 1962). Due to the income effect, an increase in the female wages may increase fertility. In contrast, the substitution effect implies that the increase in female wages may lead to a decrease in fertility, since the opportunity cost of having children rises due to the foregone earnings. Furthermore, the increase in male wages has only an income effect, if the woman is solely in charge of childrearing activities. However, since the women are gradually playing a more important role as breadwinners in their families, the income effect dominates the substitution 
effect in comparison to 30 years ago, which causes a reduction in the fertility rate.

As the participation rate of female labor force is increasing, the availability and the cost of childcare facilities are a crucial determinant in fertility behavior. Because of this tendency the fraction of children enrolled in a paid childcare center has risen within the last three decades. However, in most of the countries the childcare facilities are not subsidized by the government and the childcare costs are then an additional burden for the parents. This leads them to postpone childbearing to the times with good economic conditions and a stable income.

One possibility is that the increased availability of labor-market linked maternity benefits (e.g., partial income replacement for mothers on work-leave) has encouraged women who have yet to find permanent positions to postpone childbearing, and that this has made fertility more sensitive to economic conditions, particularly employment prospects, in recent years.

Economic theory is ambiguous about whether the fertility pattern should be countercyclical or pro-cyclical, it is necessary to analyze the relations between economic conditions and fertility empirically. In their classic analysis, Butz and Ward (1979) analyzed the fertility pattern in U.S. from 1948 to 1975 . They found a strong negative relation between women's fertility and their employment ratios. Thus, they associated good times with low fertility, since good times are the most expensive times to have children. Ermisch (1988) had a similar conclusion for UK based on the dataset from the beginning of 1950s to 1985. With the increase in women's wages the probability of having a child decreases and the unemployment rate influences the timing of childbearing. Moreover, the estimates of Ermisch (1980) on the fertility behavior in West Germany from 1935 to 1977 (excluding 1944-1957) indicated that economic growth does not lead to increase in fertility. A recent analysis of Adsera (2004) for 23 OECD countries comprising the period from 1960 to 1997, expressed reduction in fertility due to high unemployment. McNown (2003) provided similar results for the post World War II US dataset. He stressed strong positive response of fertility and female labor force participation to economic prosperity. Overall, our reading of the literature is that a mixed or counter-cyclical relationship was found up through the 1980s but that there is some suggestion of a positive or pro-cyclical relationship since then.

Other studies in this field analyzed the relation between TFR and female labor force 
participation rate. Ahn and Mira (2002) and Brewster and Rindfuss (2000) pointed out that the cross-country correlation between TFR and female labor force participation rate has reversed its sign, namely the correlation coefficient turned from a negative value before the 1980 s to a positive value. They compared the countries with different levels of female labor participation rate and concluded that the countries with higher levels of fertility have also relatively higher levels of female labor force participation rate, and vice versa.

Following this Kögel (2004) investigated whether there was a change in the sign of the time-series association between the fertility rate and the female labor force participation rate. He based the analysis on quinquennial panel dataset consisting of 21 OECD countries and comprising the period from 1960 to 2000 . He found no evidence for a change in the sign due to the country-specific factors and country heterogeneity. However, we should keep in mind that the number of time observations in this analysis was limited to eight per country, and this may lead to wrong inference about the relationship between the variables. Engelhardt et al. (2004) did a time series analysis for five industrialized countries ${ }^{1}$ comprising the same periods as in the study of Kögel (2004). The estimation results demonstrated that there is a negative and significant relation between TFR and female labor force participation rate until 1970s, and an insignificant relation afterwards. According to their argument this phenomena is due to the changes in childcare availability and attitudes towards working mothers.

The paper is organized as follows. In Section 2 we introduce the model and the data that the analysis is based on. In Section 3 we give a summary of the main estimation results. Finally, in Section 4 we conclude. We present some additional estimation results in the Appendix.

\section{Model and Data}

Our analysis is based on a panel dataset comprising the period from 1976 to 2008 . The panel dataset consists of time observations for 22 OECD countries most of which are countries from

\footnotetext{
${ }^{1}$ France, Itay, Sweden, UK, West Germany and USA.
} 
West Europe, North America and Far East Asia ${ }^{2}$. To investigate the effects of economic fluctuations on TFR, we use panel data techniques. Our aim is to analyze the effect of economic variables on fertility. We mainly want to explore the explanation of short term variations in fertility. Therefore, the analysis is based on the following first difference regression ${ }^{3}$

$$
\begin{aligned}
\operatorname{TFR}_{i t}-\mathrm{TFR}_{i, t-1}= & \beta\left(\ln x_{i, t-1}-\ln x_{i, t-2}\right)+\gamma\left[g(t) \ln x_{i, t-1}-g(t-1) \ln x_{i, t-2}\right] \\
& +\psi \mathrm{DUM}_{i, t-1} \Delta \ln x_{i, t-1}+\varepsilon_{i t}-\varepsilon_{i, t-1} \\
& i=1, \ldots, N, t=1, \ldots, T
\end{aligned}
$$

where $\mathrm{TFR}_{i t}$ is the total fertility rate for country $i$ at time $t$ and $x_{i, t-1}$ denotes the economic variable for country $i$ at time $t-1$. We include different explanatory economic variables into the model one at a time; the total unemployment rate (U), the female unemployment rate (FU) and the male unemployment rate (MU) ${ }^{4}$.

To determine the change of effects over time we specify $g(t)=t-1976$, so that the interaction $g(t)=0$ for the year 1976. Here, $\beta, \gamma, \psi$ are the unknown coefficients and $\varepsilon_{i t}$ represent the remaining disturbances. Using the first difference operator, where $\Delta y_{i t}=y_{i t}-$ $y_{i, t-1}$, we can rewrite (1) as

$$
\begin{aligned}
\Delta \mathrm{TFR}_{i t}= & \beta \Delta \ln x_{i, t-1}+\gamma \Delta g(t) \ln x_{i, t-1}+\psi \mathrm{DUM}_{i, t-1} \Delta \ln x_{i, t-1}+\Delta \varepsilon_{i t}, \\
& i=1, \ldots, N, t=1, \ldots, T
\end{aligned}
$$

We use the total unemployment rate with the rationale being that we are interested in

\footnotetext{
${ }^{2}$ Australia, Austria, Belgium, Canada, Denmark, Finland, France, Germany, Greece, Ireland, Italy, Japan, Luxembourg, Netherlands, New Zealand, Norway, Portugal, Spain, Sweden, Switzerland, UK, USA.

${ }^{3}$ In the exploration analysis we tried more complex estimators, like fixed-effects estimator and Arellano-Bond dynamic panel data estimator. The fixed effects model suffered from serial-correlation problem, which delivered inefficient results. With the dynamic panel data estimator we faced the problem of selecting the right instrumental variables. Finally, we decided to use the first-difference model because of its simplicity and parsimony. Moreover, the first difference regression, allows us to get rid of the persistent structure of the TFR and the unemployment rate.

${ }^{4}$ We would like to thank Anne Gauthier for providing us the data for TFR and the total unemployment rate (see Gauthier, 2003). The codebook which presents the sources of the individual variables can be found in the internet http://soci.ucalgary.ca/fypp/home/family-policy/databases. We collected the data for the female and male unemployment rate from the SourceOECD Database. The experiments are based on the sample from 1979 to 2008, because the male and female unemployment rates were not available until 1979 for Greece.
} 
using unemployment as a proxy for the overall state of the economy, not in understanding the individual-level effects of losing one's job on fertility. To determine the effects of economic conditions on female and male separately, we also consider the sex-specific unemployment rates. Note that unemployment rate is a better economic measure than the GDP growth in analyzing the effects of economic conditions, because one is much more interest in being employed or unemployed than the growth in the economy upon deciding to have a child. As it was reviewed in Section 1, most of the empirical papers in this field have examined the effect of the female participation rate on fertility. Since the female participation rate reflects the institutional arrangements about how the society is organized, we do not think that it is suitable indicator for the overall state of the economy. However, for comparison we report the estimation results based on the female labor force participation rate in the Appendix.

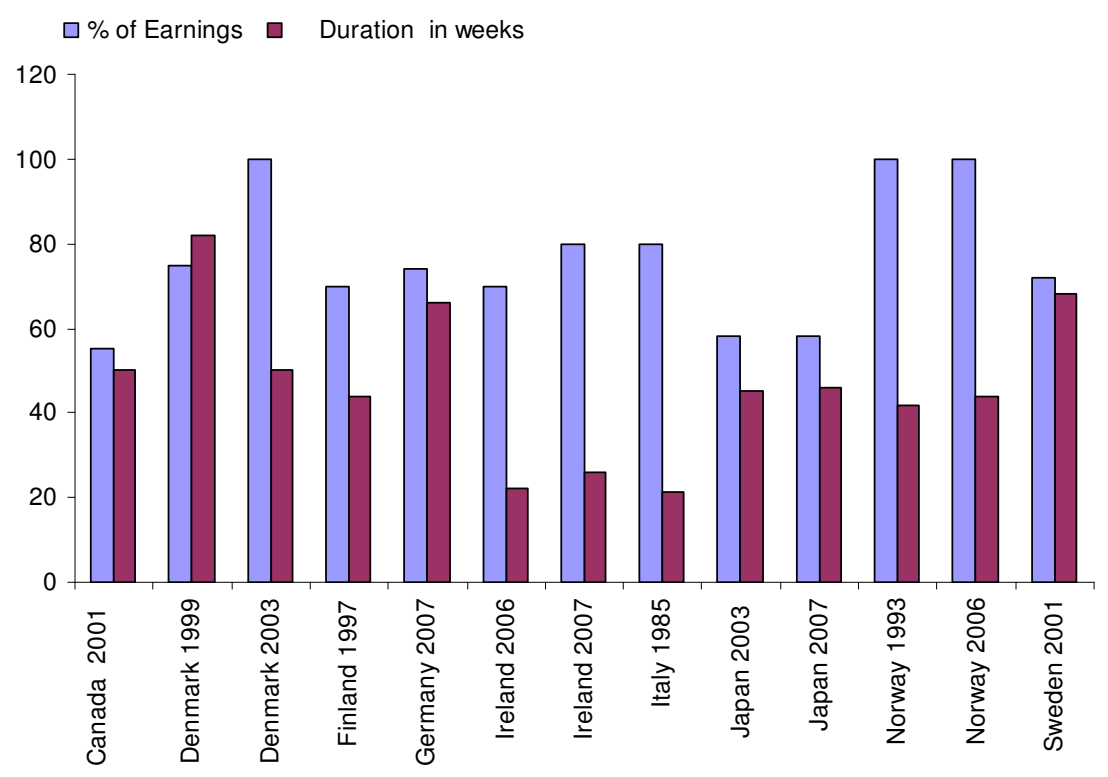

Figure 2: Earnings Related Maternity and Parental Leave Benefits (since 2001)

In addition to the explanatory economic variables, we also include a family policy dummy variable to capture the effects of the paid parental leave benefits -especially those which are related to the previous earnings- on fertility. We call the family policy dummy variable as DUM and it takes value DUM $M_{i, t-1}=1$ if there are previous earnings related parental leave benefits in country $i$ at time $t-1$ which lasts more than 20 weeks and $\mathrm{DUM}_{i, t-1}=0$ if 
otherwise ${ }^{5}$. Figure 2 displays the countries in which earnings related maternity and parental leave benefits are received more than 20 weeks. 9 out of 22 countries have earnings related parental leave benefits. Note that considering the period until 2008 neither Australia ${ }^{6}$ nor the USA had paid leave benefits. The remaining countries have introduced paid maternity leave benefits which lasts less than 20 weeks. According to Figure 2 parents get the longest paid parental leave in Sweden. The highest payment on average ${ }^{7}$ is received in Norway.

All explanatory variables are lagged by one year to account for the difference in timing between conception and birth. ${ }^{8}$

\section{Estimation Results}

For models in Table 1 we use the unemployment rate for both sexes and all ages combined. Model 1 in Table 1 demonstrates the depressing effect of the change in the lagged total unemployment rate on fertility. Note that a negative sign for the change in the unemployment rate shows the pro-cyclical fertility, which means in bad economic conditions the fertility declines. In Model 2 we interact the effects of the change in the unemployment rate with time. The specification shown in Model 2 is for a linear change in the strength of the effect. The results of Model 2 are consistent with the increasing importance of the economic variable over the time period.

With our results suggestive of some kind of structural change in the strength, and perhaps the direction of effects, we next explore to see if we can identify a time when the relationship between economic conditions and fertility may have changed. We do this by specifying time-interactions with each of the six 5-year periods in our sample. Keeping in mind that the negative sign on the change in unemployment rate is pro-cyclical in the sense that less unemployment means better economic conditions, Model 3 demonstrates that the pro-cyclical effect

\footnotetext{
${ }^{5}$ For the period from 1976 to 2000 we use the family policy database which is provided by Gauthier (2003), http://soci.ucalgary.ca/fypp/home/family-policy/databases. The data for the remaining time periods where gathered from the official web-pages of the statistical offices, ministries of health and http://www.childpolicyintl.org/.

${ }^{6}$ By 1st January 2011 Australia will introduce a paid parental leave scheme, for a maximum of 18 weeks.

${ }^{7}$ Weighted average of maternity and parental leave.

${ }^{8}$ Pregnancy lasts 9 months, but it takes some time to get pregnant. Probably, it takes most couples longer than 3 months, but less than 1 year. When working with annual data the 1 year lag is standard practice.
} 
Table 1: Effects of the Change in the Total Unemployment Rate on Fertility

\begin{tabular}{|c|c|c|c|c|c|}
\hline Variables & Model 1 & Model 2 & Model 3 & Model 4 & Model 5 \\
\hline$\Delta \ln \mathrm{U}$ & $\begin{array}{c}-0.062^{* * *} \\
(0.010)\end{array}$ & $\begin{array}{c}-0.035^{* *} \\
(0.014)\end{array}$ & $\begin{array}{c}-0.043^{* * *} \\
(0.012)\end{array}$ & $\begin{array}{c}-0.064^{* * *} \\
(0.012)\end{array}$ & $\begin{array}{c}-0.039^{* * *} \\
(0.014)\end{array}$ \\
\hline$\Delta g(t) \times \ln \mathrm{U}$ & & $\begin{array}{c}-0.002^{* * *} \\
(0.001)\end{array}$ & & & $\begin{array}{c}-0.003^{* * *} \\
(0.001)\end{array}$ \\
\hline$\Delta \ln \mathrm{U} \times \mathrm{D} 7678$ & & & 0.000 & & \\
\hline$\Delta \ln \mathrm{U} \times \mathrm{D} 7983$ & & & $\begin{array}{c}-0.013^{* *} \\
(0.007)\end{array}$ & & \\
\hline$\Delta \ln \mathrm{U} \times \mathrm{D} 8488$ & & & $\begin{array}{c}-0.021^{* * *} \\
(0.008)\end{array}$ & & \\
\hline$\Delta \ln \mathrm{U} \times \mathrm{D} 8993$ & & & $\begin{array}{c}-0.024^{* *} \\
(0.010)\end{array}$ & & \\
\hline$\Delta \ln \mathrm{U} \times \mathrm{D} 9498$ & & & $\begin{array}{c}-0.031^{* * *} \\
(0.011)\end{array}$ & & \\
\hline$\Delta \ln \mathrm{U} \times \mathrm{D} 9903$ & & & $\begin{array}{l}-0.030^{* *} \\
(0.012)^{* *}\end{array}$ & & \\
\hline$\Delta \ln \mathrm{U} \times \mathrm{D} 0408$ & & & $\begin{array}{l}-0.016 \\
(0.013)\end{array}$ & & \\
\hline $\mathrm{DUM} \times \Delta \ln \mathrm{U}$ & & & & $\begin{array}{c}0.011 \\
(0.024)\end{array}$ & $\begin{array}{c}0.025 \\
(0.025)\end{array}$ \\
\hline
\end{tabular}

Notes: $*, * *, * * *$ denote significance at the $10 \%, 5 \%$ and $1 \%$ level, respectively.

Standard errors are shown in parentheses.

of the unemployment rate has been increasing linearly over time. But there is no evidence for a significant effect during the years $2004-2008$.

To find out the effects of the previous earnings related parental leave benefits on the change in the fertility rate, we included the interaction term of the change in the unemployment rate with the family policy variable DUM into the model. Models 4 and 5 in Table 1 reveal that the depressing effect of the change in the total unemployment rate is still present. We observe that the importance of the unemployment rate increases with time, since the interaction term with time shows a significant pro-cyclical relation. Moreover, the models display that the interaction term of the change in the unemployment rate with the family policy variable does not have a significant effect on fertility. Hence, we can also conclude that the increasing effect of the economic variable is not captured by the family policy variable.

To investigate the effects of other economic indicators on the change in the fertility rate we 
Table 2: Effects of the Change in the Female Unemployment Rate on Fertility

\begin{tabular}{|c|c|c|c|c|c|}
\hline Variables & Model 1- & Model $2^{-}$ & Model 3- & Model 4- & Model 5- \\
\hline$\Delta \ln \mathrm{FU}$ & $\begin{array}{c}-0.069^{* * *} \\
(0.012)\end{array}$ & $\begin{array}{c}-0.049^{* * *} \\
(0.016)\end{array}$ & $\begin{array}{c}-0.058^{* * *} \\
(0.013)\end{array}$ & $\begin{array}{c}-0.073^{* * *} \\
(0.014)\end{array}$ & $\begin{array}{c}-0.053^{* * *} \\
(0.017)\end{array}$ \\
\hline$\Delta g(t) \times \ln \mathrm{FU}$ & & $\begin{array}{c}-0.002^{* *} \\
(0.001)\end{array}$ & & & $\begin{array}{c}-0.002^{* *} \\
(0.001)\end{array}$ \\
\hline$\Delta \ln \mathrm{FU} \times \mathrm{D} 7983$ & & & 0.000 & & \\
\hline$\Delta \ln F U \times D 8488$ & & & $\begin{array}{l}-0.008 \\
(0.005)\end{array}$ & & \\
\hline$\Delta \ln \mathrm{FU} \times \mathrm{D} 8993$ & & & $\begin{array}{l}-0.011 \\
(0.007)\end{array}$ & & \\
\hline$\Delta \ln \mathrm{FU} \times \mathrm{D} 9498$ & & & $\begin{array}{c}-0.018^{* *} \\
(0.008)\end{array}$ & & \\
\hline$\Delta \ln \mathrm{FU} \times \mathrm{D} 9903$ & & & $\begin{array}{l}-0.016^{*} \\
(0.009)\end{array}$ & & \\
\hline$\Delta \ln \mathrm{FU} \times \mathrm{D} 0408$ & & & -0.002 & & \\
\hline $\mathrm{DUM} \times \Delta \ln \mathrm{FU}$ & & & & $\begin{array}{c}0.014 \\
(0.028)\end{array}$ & $\begin{array}{c}0.021 \\
(0.028)\end{array}$ \\
\hline
\end{tabular}

insert the change in the female unemployment rate as the only economic explanatory variable in the regression model. The estimation results based on the change in the female unemployment rate are presented in Table 2. The change in the female unemployment rate has more depressing effect than the change in total unemployment rate. Additionally, we find evidence for the change in the effect over time (see Model $2^{-}$), however we do not find a significant change over all five-year periods. Only the years from 1994 to 2003 have a higher effect than the remaining periods. Model $4^{-}$and Model $5^{-}$show that the family policy variable does not respond to the economic conditions.

When we look at the results in Table 3 the pro-cyclical effect of the change in the male unemployment rate on fertility is eyecatching. Unfortunately, the results do not point out the increasing importance of the change in the male unemployment rate over time. On the contrary, the models which are exploring the response of the family policy variables to the economic conditions point out that the depressing effect of the male unemployment rate on fertility can 
Table 3: Effects of the Change in the Male Unemployment Rate on Fertility

\begin{tabular}{|c|c|c|c|c|c|}
\hline Variables & Model $1^{\circ}$ & Model $2^{\circ}$ & Model $3^{\circ}$ & Model $4^{\circ}$ & Model $5^{\circ}$ \\
\hline$\Delta \ln \mathrm{MU}$ & $\begin{array}{c}-0.065^{* * *} \\
(0.010)\end{array}$ & $\begin{array}{c}-0.056^{* * *} \\
(0.014)\end{array}$ & $\begin{array}{c}-0.058^{* * *} \\
(0.012)\end{array}$ & $\begin{array}{c}-0.075^{* * *} \\
(0.012)\end{array}$ & $\begin{array}{c}-0.065^{* * *} \\
(0.015)\end{array}$ \\
\hline$\Delta g(t) \times \ln \mathrm{MU}$ & & $\begin{array}{l}-0.001 \\
(0.001)\end{array}$ & & & $\begin{array}{l}-0.001 \\
(0.001)\end{array}$ \\
\hline$\Delta \ln \mathrm{MU} \times \mathrm{D} 7983$ & & & 0.000 & & \\
\hline$\Delta \ln \mathrm{MU} \times \mathrm{D} 8488$ & & & $\begin{array}{l}-0.006 \\
(0.005)\end{array}$ & & \\
\hline$\Delta \ln \mathrm{MU} \times \mathrm{D} 8993$ & & & $\begin{array}{l}-0.008 \\
(0.008)\end{array}$ & & \\
\hline$\Delta \ln \mathrm{MU} \times \mathrm{D} 9498$ & & & $\begin{array}{l}-0.014 \\
(0.009)\end{array}$ & & \\
\hline$\Delta \ln \mathrm{MU} \times \mathrm{D} 9903$ & & & $\begin{array}{l}-0.013 \\
(0.010)\end{array}$ & & \\
\hline$\Delta \ln \mathrm{MU} \times \mathrm{D} 0408$ & & & $\begin{array}{c}0.001 \\
(0.011)\end{array}$ & & \\
\hline $\mathrm{DUM} \times \Delta \ln \mathrm{MU}$ & & & & $\begin{array}{l}0.038^{*} \\
(0.023)\end{array}$ & $\begin{array}{l}0.041^{*} \\
(0.023)\end{array}$ \\
\hline
\end{tabular}

be partly or totally captured by the previous earnings related parental leave benefits (see Model $4^{\circ}$ and Model $5^{\circ}$ in Table 3 ).

In addition to the experiments above we also analyzed the effects of the economic variables on the tempo-adjusted fertility. The analysis is based on an unbalanced panel dataset comprising the period from 1975 to 2007 . The panel dataset consists of time observations for 16 OECD countries ${ }^{9}$. Since the analysis is not based on the same panel dataset as introduced in Section 2, we also display the estimation results with the change on the unadjusted TFR for comparison. According to the results in Table 4 even when the analysis is based on the tempo adjusted fertility rate, there is a significant pro-cyclical effect of the change in the unemployment rate, however the effect is almost half of the effect in Model 6. In other words the unemployment rate does not only lead to postponement in childbearing, but it also has a

\footnotetext{
${ }^{9}$ Austria, Denmark, Finland, France, Germany, Greece, Ireland, Italy, Japan, Netherlands, Norway, Portugal, Spain, Sweden, UK, USA.
} 
Table 4: Effects of Economic Conditions on TFR and tempo-adjusted TFR (unsmoothed)

\begin{tabular}{l|c|c|c||c|c|c}
\hline \hline & \multicolumn{3}{|c||}{ Dependent Variable $\Delta$ TFR } & \multicolumn{3}{c}{ Dependent Variable $\Delta$ adjTFR } \\
\hline Variables & Model 6 & Model 7 & Model 8 & Model 6' & Model 7' & Model 8' \\
\hline$\Delta \ln \mathrm{U}$ & $-0.082^{* * *}$ & & & $-0.044^{* *}$ & & \\
& $(0.015)$ & & & $(0.022)$ & & \\
$\Delta \ln \mathrm{FU}$ & & $-0.089^{* * *}$ & & & $-0.044^{*}$ & \\
& & $(0.015)$ & & & $(0.023)$ & \\
$\Delta \ln \mathrm{MU}$ & & & $-0.070^{* * *}$ & & & $-0.037^{*}$ \\
& & & $(0.013)$ & & & $(0.020)$ \\
\hline \hline
\end{tabular}

Notes: $*, * *, * * *$ denote significance at the $10 \%, 5 \%$ and $1 \%$ level, respectively.

Standard errors are shown in parentheses.

quantum effect. These conclusions are also true for the models with female and male unemployment rates. Both variables have a pro-cyclical effect on tempo-adjusted fertility, which means that they display in addition to the timing effect, a quantum effect.

\section{Conclusions}

The first aim of this study was to investigate whether the total fertility rate is pro-cyclical or counter-cyclical. The second aim was to analyze if and how much the effect of the economic variables on fertility changed over time. By controlling for family policy variables, we aimed to detect whether the presence of earnings related parental leave benefits eliminate the effects caused by economic conditions. An additional purpose was to examine if the economic conditions also cause similar effects on the tempo-adjusted fertility.

By using a panel dataset consisting of time observations for 22 OECD countries, we found that the effects of the economic variables on fertility are pro-cyclical, in other words in good economic conditions fertility increases, whereas bad economic conditions lead to a decline in fertility. Our results show that the estimation results of Butz and Ward (1979) are controversial, in other words maybe there wasn't a counter-cyclical relation between fertility and economic conditions (see also Macunovich, 1995).

In the analysis, we used the total unemployment rate as a proxy to reflect the good and 
bad economic conditions ${ }^{10}$. Moreover, we detected that the pro-cyclical effect of the unemployment rate increases over time until 2004. The presence of an earnings related parental leave benefit do not capture the effects of the economic conditions. This may be due to the fact that most of the job contracts are temporary.

Both female and male unemployment rates have pro-cyclical effects on fertility. While we found evidence for the increasing importance of the female unemployment rate over time, we did not detect a change in the influence of the male unemployment rate. Furthermore, the presence of the earnings related parental leave benefits captures partly the depressing effect of the male unemployment rate. In contrast, there is not such a significant relation with the female unemployment rate.

Finally, we showed that the good and bad economic conditions do not only effect the timing of the childbearing, but they also have a quantum effect.

\section{References}

Adsera, A. (2004). Changing fertility rates in developed countries. The impact of labor market institutions. Journal of Population Economics, 17, 17-43.

Ahn, N., Mira, P. (2002). A note on the changing relationship between fertility and female employment rates in developed countries. Journal of Population Economics, 15, 667-682.

Becker, G. (1960). An economic analysis of fertility. In Demographic and Economic Change in Developed Countries, pages 209-231. Princeton: National Bureau of Economic Research.

Becker, G. S., Lewis, H. G. (1973). On the interaction between the quantity and quality of children. Journal of Political Economy, 81, 279-288.

Brewster, K. L., Rindfuss, R. R. (2000). Fertility and women's employment in industrialized nations. Annual Review of Sociology, 26, 271-296.

\footnotetext{
${ }^{10} \mathrm{We}$ did other estimations using the GDP growth and the female-to-male wage ratio. But the results were either insignificant or ambiguous, so we didn't include these results.
} 
Butz, W., Ward, M. P. (1979). The emergence of countercyclical U.S. fertility. The American Economic Review, 69, 318-328.

Engelhardt, H., Kögel, T., Prskawetz, A. (2004). Fertility and women's employment reconsidered: A macro-level time-series analysis for developed countries, 1960-2000. Population Studies, 58, 109-120.

Ermisch, J. F. (1980). Time costs, aspirations and the effect of economic growth on German fertility,". Oxford Bulletin of Economics and Statistics, 42, 125-143.

Ermisch, J. F. (1988). Econometric analysis of birth rate dynamics in Britain. Journal of Human Resources, 23(4), 563-76.

Gauthier, A. H. (2003). Comparative family benefits database, Version 2. University of Calgary, On-line.

Kögel, T. (2004). Did the association between fertility and female employment within OECD countries really change its sign? Journal of Population Economics, 17, 45-65.

Macunovich, D. J. (1995). The Butz-Ward fertility model in the light of the more recent data. The Journal of Human Resources, 30, 229-255.

McNown, R. (2003). A cointegration model of age-specific fertility and female labor supply in the United States. Southern Economic Journal, 70(2), 344-358.

Mincer, J. (1962). Labor force participation of married women: a study of labor supply. In H. G. Lewis, editor, Aspects of Labor Economics, pages 1-35. Princeton, N.J.: Princeton University Press.

Mincer, J. (1963). Market prices, opportunity costs, and income effects. In C. Christ, editor, Measurement in Economics, page 3652. Stanford, CA: Stanford University Press. 
Table 5: Effects of the Change in the Female Labor Force Participation on Fertility

\begin{tabular}{l|c|c|c|c|c}
\hline \hline Variables & Model 1' & Model 2' & Model 3' & Model 4' & Model 5' \\
\hline$\Delta \ln$ FLP & $-0.131^{*}$ & -0.009 & -0.113 & $-0.159^{* *}$ & -0.037 \\
& $(0.073)$ & $(0.086)$ & $(0.075)$ & $(0.077)$ & $(0.088)$ \\
& & $-0.001^{* * *}$ & & & $-0.001^{* * *}$ \\
$\Delta \ln \mathrm{FLP} \times \mathrm{D} 7678$ & & $(0.0005)$ & & & $(0.0005)$ \\
& & & 0.000 & & \\
$\Delta \ln \mathrm{FLP} \times \mathrm{D} 7983$ & & & -0.002 & & \\
& & & $(0.003)$ & & \\
$\Delta \ln \mathrm{FLP} \times \mathrm{D} 8488$ & & & $-0.008^{* *}$ & & \\
& & & $(0.004)$ & & \\
$\Delta \ln \mathrm{FLP} \times \mathrm{D} 8993$ & & & $-0.008^{*}$ & & \\
& & & $(0.005)$ & & \\
$\Delta \ln \mathrm{FLP} \times \mathrm{D} 9498$ & & & $-0.013^{* *}$ & & \\
$\Delta \ln \mathrm{FLP} \times \mathrm{D} 9903$ & & & $(0.005)$ & & \\
$\Delta \ln \mathrm{FLP} \times \mathrm{D} 0408$ & & & $-0.011^{*}$ & & \\
& & & $-0.006)$ & & \\
$\mathrm{DUM} \times \Delta \ln \mathrm{FLP}$ & & & $(0.007)$ & & \\
& & & & 0.312 & 0.368 \\
& & & & $(0.255)$ & $(0.255)$ \\
\hline \hline
\end{tabular}

Notes: $*, * *, * * *$ denote significance at the $10 \%, 5 \%$ and $1 \%$ level, respectively. Standard errors are shown in parentheses.

\section{Appendix}

We repeated the experiments using the change in the female labor force participation rate (FLP) as the explanatory economic variable ${ }^{11}$. Model 1' in Table 5 shows that at the $10 \%$ significance level the FLP has a negative effect on fertility, which means that with the increase in the number of females on the job market, fertility declines. However, the weak relation between these two variables disappear when the interaction term of FLP with time is inserted into the model.

The estimation results for Model 2' indicate a statistically strong but numerically weak increasing effect of FLP over time. When we consider the results for Model 3' it is obvious

\footnotetext{
${ }^{11}$ Gauthier (2003) provided us the data for the female labor force participation rate. The codebook which presents the sources of the data can be found in the internet http://soci.ucalgary.ca/fypp/home/family-policy/databases.
} 
that the significant negative effect of female labor force participation rate in 1980s is vanishing at the beginning of the 21th century. The reduction in the effect of the female labor force participation rate may be due to the introduction of previous earnings related parental leave benefits. This may have encouraged women to combine work and childbearing. A closer look at the estimation results with family policy variables will allow us to understand the mechanisms behind this outcome in a better way. Models 4' and 5' show the estimation results with the family policy variables. The depressing effect of the female labor force participation rate is present in Model 4'. However the effect of $\Delta$ ln FLP disappears with the inclusion of the interaction term. (see Model 5' in Table 5). The introduction of the interaction term of FLP with time causes an increasing negative effect over time. Once again we do not detect the response of the family policy variable to the economic conditions, since the estimates on $\mathrm{DUM} \times \Delta \operatorname{lnFLP}$ are insignificant. 